\title{
Continued Sexual Risk Behaviour in African American and Latino Male-to- Female Transgender Adolescents Living with Hiv/Aids: A Case Study
} Nancy Van Devanter*, Alexandra Duncan, Victoria H. Raveis, Jeffrey Birnbaum, Tiphani Burrell-Piggott and Karolynn Siegel New York University, College of Nursing, 726 Broadway, Room 1049, New York

\begin{abstract}
Purpose: This study examined the social and contextual factors associated with continued high risk sexual behaviors among male-to-female transgender (MTFTG) adolescents living with HIVIAIDS. The study is part of a larger qualitative study of 59 racial/ethnic minority adolescents living with HIVIAIDS.

Methods: In-depth focused interviews were conducted with five MTFTG adolescents (16-24 years) living with HIV. Content analysis was conducted to identify themes related to continued sexual risk behaviors.

Results: Four out of five of MTFTG adolescents reported inconsistent condom use since their HIV diagnosis. Transgender stigma contributed to financial vulnerability leading to the adoption of sex work to support themselves. Sex and drugs were used to manage transgender stigma and sexual risk-taking with sex work partners was influenced by financial vulnerability.
\end{abstract}

Conclusions: MTFTG adolescents with HIV have unique psychosocial needs related to transgender stigma and structural needs to decrease financial vulnerability that contribute to risky sexual behavior.

Keywords: Adolescents; Transgender stigma; HIV/AIDS; Sex work

Abbreviations: MTFTG: Male-to-Female Transgender

\section{Introduction}

Male-to-female transgender (MTFTG) adolescents are at very high risk for HIV/AIDS [1]. In a recent study of 151 MTFTG adolescents, 19\% reported being HIV positive [2]. Research suggests that MTFTG persons of color have higher HIV rates and report more sexual risk behaviors than their white counterparts [3-5]. Despite high rates of HIV and risky sexual behaviors, MTFTG adolescents are an understudied group. Even less attention has been focused on the additional complexities MTFTG adolescents of color encounter. Understanding factors that influence risky sexual behavior in this population is essential to developing interventions to prevent secondary HIV transmission. The purpose of this brief report is to examine the social and contextual factors that influence sexual behavior in HIV positive MTFTG adolescents of color.

\section{Methods}

The data reported here are part of a larger qualitative study of the illness-related adaptive tasks and coping responses of African American and Latino adolescents with behaviorally acquired HIV. Fifty-nine adolescents from five adolescent HIV specialty clinics in the New York metropolitan area completed an in-depth qualitative interview and a brief quantitative survey. Qualitative interviews were audiotaped, transcribed verbatim, coded, and content analyzed utilizing ATLAS. ti 4.2. Further description of the methodology has been presented elsewhere [6]. The study was approved by the Columbia University and New York University Institutional Review Boards (IRBs), the IRBs of collaborating institutions, and received a Federal Certificate of Confidentiality. The present analysis focuses on the five adolescents of color with HIV who identified as MTFTG. All were infected through risky sexual behavior and have been diagnosed with HIV.

\section{Results}

Four of the five MTFTG participants reported inconsistent condom use with their sexual partners some or all of the time since their HIV diagnosis. The fifth reported regular condom use with her current partner. Three themes related to their current and past sexual risk behavior emerged from the participants' narratives: (1) Transgender stigma contributes to financial vulnerability leading to sex work; (2) Sex and drugs are used to manage transgender stigma; and (3) Financial vulnerability influences sexual risk-taking with clients.

Transgender stigma contributes to financial vulnerability leading to sex work

The MTFTG participants reporting high sexual risk behavior were engaged in sex work to support themselves. Rejection by family, school, housing and work environments, due to their transgender identity, generated financial vulnerability. One youth reported having dropped out of high school because of sexual discrimination. Two others left due to stress related to their gender transition. As one 18 year-old participant explained: "I didn't really like school. It's like people knew I was gay and I was trying to hide it.... It's like people knew- they'll say 'that's a fag...' I'm trying not to take it too hard but that's when things started going downhill. I started messing with drugs-skipping school, doing drag." All three dropouts reported that they subsequently initiated sex work to support themselves. Another adolescent started sex work when her mother threw her out of the house because of her

*Corresponding author: Nancy Van Devanter, DRPH, MPH, EdM, RN, associate professor, New York University, College of Nursing, 726 Broadway, Room 1049, New York, NY 10003, Tel: 212.998.5328; Fax: 212.995.4561, E-mail: nvd2@nyu.edu

Received October 19, 2011; Accepted December 02, 2011; Published December 20, 2011

Citation: Van Devanter N, Duncan A, Raveis VH, Birnbaum J, Burrell-Piggott T, et al. (2011) Continued Sexual Risk Behaviour in African American and Latino Male-toFemale Transgender Adolescents Living with Hiv/Aids: A Case Study. J AIDS Clinic Res S1:002. doi:10.4172/2155-6113.S1-002.

Copyright: @ 2011 Van Devanter N, et al. This is an open-access article distributed under the terms of the Creative Commons Attribution License, which permits unrestricted use, distribution, and reproduction in any medium, provided the original author and source are credited. 
gender identity: "I go outside at night and make my money...I don't want to say prostitute but- I'd rather say hustler."

\section{Sex and drugs are used to manage transgender stigma}

The participants' accounts detailed how they and other transgender adolescents turned to sex and drugs to manage transgender stigma. As one participant related: "Like I said, I didn't have to live my life like that, having sex with all these different guys to make myself feel good. I deals with a lot of 'trans' (transgender adolescents) and they do that. They self-esteem be low. And mines used to be low, but I used to do it with drugs...like their drug habit was sleeping with different guys; my drug habit was doing drugs."

\section{Financial vulnerability influences sexual risk-taking with clients}

Discussion of sexual decision-making behavior documented that financial needs impacted their risk-taking. One participant explained: "If the price is right and I feel comfortable I'll do whatever it takes." She explained further that she usually charges $\$ 50$ for oral sex and $\$ 100$ for anal sex, but has charged as low as $\$ 20$ for oral sex and $\$ 50$ for anal sex "when money is tight".

\section{Discussion}

Four of the five MTFTG adolescents of color with HIV report currently engaging in extremely risky behaviors involving sex work, drugs, and inconsistent condom use, compared to $26 \%$ of MSM in the same study who reported high risk behavior [6]. Their narrative accounts reveal a history of multiple life stressors related to their transgender identity including rejection by families, friends, school and work environments, unstable housing, lack of education and job skills. Their engagement in sex work is driven by economic and housing instability [1]. Further, this groups' use of drugs and sex to manage stigma related to their gender identity, HIV diagnosis and minority status generates an additional need for money to acquire drugs, as well as increasing risky sexual behavior [7]. Studies note many unmet psychosocial needs among minority MTFTG adolescents due to the stigma, harassment and social isolation they experience because of their female gender identification [8,9]. To better address the needs of MTFTG adolescents of color with HIV, cultural sensitivity to both their transgender and racial/ethnic experiences is essential. For example, hormone treatment may be a high priority for this population. Studies have indicated that hormone therapy for feminization may allow MTFTG persons to feel more comfortable with their gender identity [1]. Attending to this need may be a means of engaging this population in interventions focused on limiting HIV transmission. Efforts that target this sub-population should be multi-faceted to address not only their clinical issues, but also meet their complex and interrelated psychosocial, mental health, educational, and vocational needs.

\section{Limitations}

The sample is small and not necessarily representative of all MTFTG adolescents living with HIV. Youth in this study were connected to HIV-related care. MTFTG adolescents unaware of their HIV diagnosis, and those living with HIV/AIDS but not in medical care, may have higher sexual risk behaviors and a greater need for services.

\section{Acknowledgement}

The study was supported by funding from the National Institute for Child Health and Human Development 5 R01HD041891. The authors thank Craig Fryer, Julie Stein, Mary Irvine, Nana Mensah, Amy Bleakley, Sonya Romanoff and Destiny Ramjohn for their assistance in data collection, transcription, coding, and data management, Dr. Alwyn Cohall and the staff of Project STAY New York Presbyterian Hospital, the staff of Project HEAT SUNY Downstate Medical Center, Dr. Linda Levin and the staff of Mount Sinai Adolescent Health Program, Dr. Robert Johnson and the staff of UMDNJ Division of Adolescent Young Adult Medicine, and Dr. Donna Futterman and the staff of the Adolescent AIDS Program at Montefiore Medical Center. We would like to express our deep gratitude for the young men and women who shared their experience and insights about living with HIV.

\section{References}

1. Garofalo R, Deleon J, Osmer E, Doll M, Harper GW (2006) Overlooked, misunderstood and at-risk: Exploring the lives and HIV risk of ethnic minority male-to-female transgender adolescents. J Adolesc Health 38: 230-236.

2. Wilson EC, Garofalo R, Harris RD, Herrick A, Martinez M, et al. (2009) Transgender female adolescents and sex work: HIV risk and a comparison of life factors related to engagement in sex work. AIDS Behav 13: 902-913.

3. Herbst JH, Jacobs ED, Finlayson TJ, McKleroy VS, Neumann MS, et al. (2008) Estimating HIV prevalence and risk behaviors of transgender persons in the United States: A systematic review. AIDS Behav 12: 1-17.

4. Nemoto T, Operario D, Keatley J, Han L, Soma T (2004) HIV risk behaviors among male-to-female transgender persons of color in San Francisco. Am J Public Health 94: 1193-1199.

5. Clements-Nolle K, Marx R, Guzman R, Katz M (2001) HIV prevalence, risk behaviors, health care use, and mental health status of transgender persons: Implications for public health intervention. Am J Public Health 91: 915-921.

6. VanDevanter N, Duncan A, Burrell-Piggott T, Bleakley A, Birnbaum J, et al (2011) The influence of substance use, social sexual environment, psychosocial factors, and partner characteristics on high-risk sexual behavior among young Black and Latino men who have sex with men living with HIV: A qualitative study. AIDS Patient Care STDs 25: 113-121.

7. McKirnan DJ, Vanable PA, Ostrow DG, Hope B (2001) Expectancies of sexual "escape" and sexual risk among drug and alcohol-involved gay and bisexual men. J Subst Abuse 13: 137-154.

8. Grossman AH, D'Augelli AR (2006) Transgender adolescents: Invisible and Vulnerable. J Homosex 51: 111-112.

9. Bith-Melander P, Sheoran B, Sheth L, Bermudez C, Drone J, et al. (2010) Understanding sociocultural and psychological factors affecting transgender people of color in San Francisco. J Assoc Nurses AIDS Care 21: 207-220. 